\title{
AS CONDIÇÕES DA AÇÃO NO CÓDIGO DE PROCESSO CIVIL ${ }^{1}$
}

\section{THE CONDITIONS OF ACTION IN THE CIVIL PROCEDURE CODE}

Paulo Afonso Brum Vaz Desembargador Federal, Mestre em Poder Judiciário (FGV), Doutor em Direito Público (UNISINOS), Pós-doutorando do IGC - Centro de Direitos Humanos da Universidade de Coimbra, Portugal, membro da Academia Brasileira de Direito da Seguridade Social - ABDSS, Professor de Direito Processual Civil da Escola Superior da Magistratura Federal de Santa Catarina. Florianópolis, Santa Catarina, Brasil. Email: paulofonsov4@gmail.com

\section{Gabriela Grock}

Pós-graduanda em Jurisdição Federal pela Escola Superior da Magistratura Federal de Santa Catarina. Florianópolis, Santa Catarina, Brasil. E-mail. gabriela.grock@hotmail.com

RESUMO: O presente artigo analisa a situação das condições da ação no Código de Processo Civil de 2015, no tocante à sua manutenção e ao momento de sua verificação, em razão das repercussões de ordem teórico-prática que surgem, sobretudo, na formação ou não da coisa julgada material. Objetiva-se, a partir de breve retrospectiva da evolução das teorias da ação, do texto do novo CPC e da doutrina abalizada, desvelar os efeitos da declaração de carência de ação em diferentes momentos processuais, focando especialmente numa consequência indesejada que pode ser a impossibilidade de repropositura da ação diante da sentença terminativa, com reflexos na Ação Rescisória. A partir de uma análise sistêmica, conclui-se que as condições da ação permanecem, ainda que veladamente, no novo diploma processual, e que, independentemente do momento da declaração de carência de ação por ausência de condições da ação, a sentença será

\footnotetext{
${ }^{1}$ Artigo recebido em 13/08/2020 e aprovado em 29/10/2020.
} 
terminativa e não fará coisa julgada material, sob pena de violação de direitos e garantias dos litigantes, notadamente do due process of law em seu viés procedural.

PAlaVRaS-ChAVE: Condições da ação. Novo Processo Civil. Teorias da ação. Coisa julgada. Ação Rescisória.

ABSTRACT: The present paper analyzes the situation of the conditions of action in the Civil Procedure Code of 2015. It relates to its maintenance and the moment of verification, due to repercussions of practical-theoretical order that rise mostly from creating or not a material res judicata. The aim is to reveal the effects of lack of action declarations in different procedural moments. It focuses especially on an unintended consequence, which may be the impossibility of repropositioning the action in the face of the final sentence and causing effects on the Rescission Action. In order to do so, the study looks back on the evolution of theories of action, the text of the new Civil Procedure Code and on the considered doctrine. From a systemic analysis, it is concluded that the conditions of action remain surreptitiously in the new procedural document. Independently from the moment of the lack of action declaration by absence of action conditions, the sentence will be decisive and will not create the material res judicata under penalty of violating the rights and securities of the litigant notably from the due process of law in its procedural bias.

KEY WORDS: Conditions of action. New Civil Procedure Code. Theories of action. Res judicata. Rescission action.

\section{INTRODUÇÃO}

Este artigo objetiva enfrentar um tema polêmico e de extrema relevância no Direito Processo Civil brasileiro, a saber: as condições da ação, instituto fundamental da processualística, que recebeu no CPC de 2015 uma disciplina processual diversa daquele que lhe dedicara o CPC revogado. Uma olhada superficial permite ver que a própria 
denominação "condições da ação", antes expressamente referida, não é mais encontradiça no novo $\mathrm{CPC}$, conquanto o art. 17 condicione a postulação em juízo à legitimidade $a d$ causam e ao interessede agir, cominando a pena de carência de ação, ou seja, a extinção do processo sem exame de mérito (sentença terminativa), quando se verificar ausência de legitimidade para a causa ou de interesse de agir (art. 485, VI), sem mais cogitar a (im)possibilidade jurídica do pedido.

Pretende-se enfocar, a partir da revisão bibliográfica e à luz da jurisprudência, o alcance e as possíveis repercussões da referida mudança, na perspectiva das chamadas teorias da ação (Clássica ou Imanentista, Autonomista, Eclética ou Assercionista), notadamente diante dos reflexos práticos que a adoção de uma ou de outra proporcionam. No campo da prática judicial, é preciso dirimir as dúvidas consequentes da reforma: em que momento cumpre examinar a presença das condições da ação? Este exame constitui decisão terminativa (sem exame de mérito) ou definitiva (com exame de mérito)? Qual o destino da (im)possibilidade jurídica do pedido? A questão fulcral é mesmo a coisa julgada (formal ou material?), que recebeu também disciplina diversa no novo código quanto às decisões processuais (terminativas), tendo sua práxis impactada pela natureza da sentença que venha a reconhecer a carência de ação, inclusive no que concerne à propositura da eventual Ação Rescisória, na redação do $§ 2^{\circ}$ do art. 966 do novo CPC. Esta é a proposta do presente ensaio: discutir e encontrar respostas razoáveis e técnicas para tais questionamentos, aprofundando e enriquecendo o debate sobre o "novo processo civil".

\section{TEORIAS DA AÇÃO - DO IMANENTISMO AO ASSERCIONISMO}

Com vistas ao adequado enfrentamento da temática, impende levar a cabo uma breve resenha acerca das teorias da ação e suas respectivas críticas, para, ao final, situar-se o sistema adotado pelo novo Código de Processo Civil.

Para a Teoria Clássica Civilista ou Imanentista, o direito de ação é um apêndice do direito material, dele se diferenciando pelo movimento. "A ação nada mais é do que o direito de alguém perseguir em juizo o que lhe é devido" (Savigny)². O Código Civil de

\footnotetext{
${ }^{2}$ SAVIGNY, Friedrich Carl Von. Sistema del diritto romano attuale. Trad. Vittorio Scialoja. v. 5. Torino:
} Utet, 1893. 
1916 dizia, em seu art. 75, que "a todo direito corresponde uma ação, que o assegura". A ação não existe como direito autônomo, mas constitui um dos modos como pode ser exercitado o direito subjetivo privado (Calamandrei) ${ }^{3}$. Ação é o próprio direito posto em movimento, é o direito em estado de ação em vez de ser o direito em estado de descanso, o direito em guerra em vez de o direito em paz (o próprio direito reagindo a uma violação. A crítica à Teoria Imanentista dá-se diante da ausência de enquadramento das ações meramente declaratórias, que visam à mera declaração da existência ou não de uma relação ou situação jurídica ou à autenticidade ou falsidade de um documento. A Teoria Clássica Civilista (imanentista) deixa uma lacuna quanto às ações cujo demandante não tem razão, isto é, aquelas em que o autor não é detentor do direito material alegado. No juízo de improcedência, portanto, não haveria o direito de ação? Não haveria direito sem ação, nem ação sem direito? ${ }^{4}$

O debate entre os romanistas Windscheid e Muther marca o início da superação da confusão entre direito lesado e ação, propondo Muther a distinção entre os dois direitos de natureza pública, abrindo o caminho para a Teoria Autonomista, que sustenta a independência do direito processual em relação ao direito material. ${ }^{5}$ Para a chamada Teoria Autônoma concreta, cujos expoentes são Wach, Bülow, Hellwig e Chiovenda, ${ }^{6}$ a ação é o direito concreto à tutela jurisdicional, ou seja, um direito público subjetivo diverso do direito material lesado, mas só existente quando também se fizer presente o próprio direito material a tutelar. A ação seria então o direito à sentença favorável. Em outro dizer, um direito público voltado contra o Estado, de obter uma proteção pública para o direito subjetivo material. A crítica à teoria autonomista reside no aprisionamento do direito de ação ao reconhecimento do direito material, condicionando-o a um pronunciamento de mérito favorável.

\footnotetext{
${ }^{3}$ CALAMANDREI, Piero. Istituzioni di diritto processuale civile. Pádua: Cedam, 1943.

4 Ver CINTRA, Antônio Carlos Araújo; DINAMARCO, Cândido Rangel; GRINOVER, Ada Pellegrini. Teoria geral do processo. 7. ed. - São Paulo: RT, 1990, p. 221-222.

5 WINDSCHEID, Bernard; MUTHER, Theodor. Polémica sobre la “actio”. Trad. Tomás A. Banzhaf. Buenos Aires: Ejea, 1974.

${ }^{6}$ Chiovenda, em 1903, criou a teoria do direito de ação potestativo e não subjetivo: ação como direito autônomo diverso do direito material, mas não dirigido contra o Estado, sim contra o adversário. A ação como poder jurídico de dar vida à condição para atuação da vontade da lei (CHIOVENDA, Giuseppe. $L a$ acción en el sistema de los derechos. Trad. Santiago Sentís Melendo. Valparaíso (Chile): Edeval, 1992).
} 
A Teoria Autônoma abstrata, de Plósz e Degenkolb, ${ }^{7}$ amplia a autonomia de modo que o direito de ação alcança também o direito de receber uma sentença de improcedência. Tenho o direito de ação, mas posso não ter o direito material! O "direito de agir" que obrigaria o réu a participar do processo, independentemente de o autor possuir ou não o direito material. O direito de agir estaria legitimado por um direito público subjetivo anterior à relação jurídica instaurada entre as partes, sendo completamente desnecessária a afirmação do direito material (pretensão)para a configuração de seu exercício. O direito de ação é dirigido em face do Estado, sendo este o sujeito passivo de tal direito. Não se cogita de condições ao exercício da ação, porquanto inexiste a vinculação com a prestação jurisdicional favorável. O pecado da Teoria Autonomista é incentivar o procedimentalismo em detrimento do substancialismo e pregar uma função demasiadamente instrumental do processo, além de mostrar-se inconcebível que o juiz figure como titular passivo da ação. ${ }^{8}$

A Teoria eclética, de E. T. Liebman, ${ }^{9}$ procura fundir abstracionismo e concretismo. O direito de ação é um direito público condicionado à presença das condições da ação: interesse de agir, legitimidade ad causam e possibilidade jurídica do pedido, aferidos em face da situação jurídica de direito material. Ação e atuação jurisdicional estariam imbricadas, de modo que a falta de uma condicionante conduziria à carência do exercício da jurisdição (ação). A função jurisdicional se exerceria diante do pronunciamento judicial de mérito, ou seja, sobre a pretensão de direito material deduzida em juízo. O objetivo manifesto da teoria eclética seria evitar ações natimortas, como medida de economia processual, mas com a possibilidade de reconhecimento a qualquer tempo. O momento processual é o senhor do tipo de extinção do processo, com ou sem exame de mérito. Para Liebman, o direito de ação é abstrato quanto ao seu resultado, pois não está condicionado

\footnotetext{
${ }^{7}$ Dagenkolb na Alemanha, em 1877, e Plósz, na Hungria, em 1876.

${ }^{8}$ Rocco, na Itália, foi um dos defensores da teoria autonomista (interesses primário e secundário). Também, no Uruguai, Couture, referindo-se a um "direito de petição" (COUTURE, Eduardo. Introducción al Estudio Del Proceso Civil. Buenos Aires: Editorial Depalma, 1949, p. 19). Sobre a crítica desta corrente, por todos, ver CINTRA, Antônio Carlos Araújo; DINAMARCO, Cândido Rangel; GRINOVER, Ada Pellegrini. Teoria geral do processo. 7. ed. - São Paulo: RT, 1990, p. 226.

${ }^{9}$ Liebman define o direito de ação como direito subjetivo de fundo constitucional instrumental, equiparandoo a um poder de agir genérico e abstrato assegurado pela Constituição, ao qual corresponde a obrigação do Estado, igualmente interessado na distribuição da justiça, e correlato com a sujeição e instrumentalidade inerentes a uma pretensão material (LIEBMAN, Enrico Tullio. Manual de Direito Processual Civil. Trad. e notas de Cândido R. Dinamarco. 2. ed. - Rio de Janeiro: Forense, 1985, p. 151e sgts).
} 
ao julgamento de procedência. No entanto, revela-se concreto quanto ao seu nascimento, na medida em que só existe de verdade quando se fizerem presentes as condições da ação.

Surgiu, como corolário, a técnica da exposição ou comprovação, em que as condições da ação não devem ser aferidas apenas em razão da afirmação do autor, cabendo também a sua análise diante das provas, pouco importando a fase processual em que isso possa ocorrer no processo. As condições da ação, portanto, devem ser apreciadas no começo do processo (fase postulatória), a partir da afirmação do autor (in statu assertionis), ou ainda aferidas segundo o que vier a ser comprovado no processo, após o exame das provas.

A Teoria Eclética de Liebman foi incorporada pela sistemática processual brasileira, no CPC de $73,{ }^{10}$ recebendo a adesão de insignes processualistas, mas também a crítica implacável de processualistas de nomeada (F. Didier, Marinoni e outros). Segundo dizem, visceralmente analisada, a teoria apresenta incongruências irrespondíveis, como o condicionamento do exercício do direito de ação a um pronunciamento de mérito (de procedência ou improcedência da pretensão de direito material). ${ }^{11}$

Ao atrelar os conceitos de jurisdição, ação e processo de modo que nenhum deles pode sequer existir - muito menos se manifestar na prática - sem os demais, suprimindo o caráter jurisdicional da decisão de carência de ação, que não ocorreria no âmbito do processo, pois Liebman só enxerga jurisdição na sentença que examina o mérito, o jurista italiano deixa fissuras abertas em sua teoria, não definindo com clareza e precisão o caráter das atividades precedentes. As condições da ação devem ser aferidas de acordo com a afirmação feita pelo autor na petição inicial. Se essa afirmação do autor corresponde à

\footnotetext{
${ }^{10}$ Explicito o art. 267. Extingue-se o processo, sem julgamento do mérito: (...) VI - quando não concorrer qualquer das condições da ação, como a possibilidade jurídica, a legitimidade das partes e o interesse processual; (...)".

${ }^{11} \mathrm{O}$ festejado processualista italiano Salvatore Satta, nada obstante reconheça a distinção entre a ação e o direito material, atribui a ambos a mesma natureza substancial, considerando-os como realidades indissociáveis. Não se pode vislumbrar a existência de um direito objetivo ou subjetivo "antes e além da ação". [...] Se o juiz disser que a ação não tem razão de ser, dirá que o ordenamento se concretizara (a ação do réu se era adequada), mas o dirá através de um juízo que será sempre aquele que concretizará o ordenamento (SATTA, Salvatore. Direito Processual Civil. Trad. Luiz Autuori. 7. ed., Rio de Janeiro: Editor Borsoi, 1973, v. 1, p. 162).
} 
realidade, isso já constitui questão de mérito, porquanto o direito à tutela jurisdicional não depende da existência do direito material, mas somente da afirmação do direito. ${ }^{12}$

O professor Calmon de Passos, por outro lado, enxergava na ação um poder genérico de provocar a atividade jurisdicional do Estado. Esse poder, com a propositura da demanda, se transforma em direito subjetivo, fazendo nascer, em primeiro plano, a obrigação do juiz de prolatar uma decisão, e, em segundo plano, a sujeição do demandado ao poder jurisdicional do Estado. Assim, o direito de ação não seria nem direito à sentença favorável, nem à sentença de mérito, todavia, pura e simplesmente, direito a uma decisão, com conteúdo variável conforme os elementos levados ao processo pelas partes. Vislumbrava o insigne processualista:

\begin{abstract}
uma ação de tutela meramente processual, que se exaure, desobrigando o órgão jurisdicional, com um provimento de inadmissibilidade; uma ação de tutela do direito objetivo material, que se exaure, desobrigando o órgão jurisdicional com a certificação do direito objetivo e sua conseqüente atuação; e uma ação de tutela do direito subjetivo material, que somente se exaure, desobrigando o órgão jurisdicional, com a satisfação do direito subjetivo do demandante. ${ }^{13}$
\end{abstract}

Com o fito de colmatar as deficiências da Teoria Eclética, surgiu a Teoria da Asserção, apregoando que a análise das condições da ação estaria restrita ao juízo de admissibilidade inicial que o magistrado exerce diante das afirmações feitas pelo autor. Se a ausência de uma das condições da ação fosse detectada na fase postulatória, estar-seia diante da carência da ação e o processo seria extinto sem resolução do mérito, nos termos do artigo 267, VI, do CPC/73, e não teríamos o fenômeno da coisa julgada, podendo a mesma ação ser novamente proposta. Nesta divisão, toda a matéria tomada como verossímil e relegada para a fase instrutória consubstanciaria análise de mérito e faria coisa julgada material, impedindo a reapreciação da matéria pelo Judiciário, tal como sustentam Marinoni, Arenhart e Mitidiero, ${ }^{13}$ entre outros.

\footnotetext{
${ }^{12}$ Para Luiz Guilherme Marinoni, ao criar a teoria eclética, Liebman colocou-se "na metade do caminho daqueles que, de um lado, entendem que a ação depende do efetivo reconhecimento do direito material, e daqueles outros que sustentam que a ação é um direito de agir totalmente abstrato" (MARINONI, Luiz Guilherme. Curso de processo civil: teoria geral do processo(v.1). 6. ed. - São Paulo: Revista dos Tribunais, 2012, p. 175).

${ }^{13}$ CALMON DE PASSOS, J. J. A Ação no Direito Processual Civil Brasileiro. Livraria Progresso Editora, 1961, p. 146.
} 
Doutrinariamente, esta posição também é sustentada pelo professor José R. dos Santos Bedaque, que diferencia as condições da ação do mérito pela profundidade da cognição exercida pelo juiz. "se as condições da ação são aferidas a partir de elementos da relação material; se a ausência de uma delas, mesmo verificada in statu assertionis, mediante cognição sumária, mas suficiente, implica solução parcial do litígio". ${ }^{14}$

Em sede de jurisprudência, no âmbito do Superior Tribunal de Justiça, embora alguns julgados refiram expressamente que o Tribunal aderiu à Teoria Assercionista, temse notado que, na verdade, as vezes em que assim o fez constituem a retumbante minoria dos julgados, podendo ser contados nos dedos. Vejam-se os seguintes julgados:

“[...] se o juiz realizar a cognição profunda sobre as alegações contidas na petição, após esgotados os meios probatórios, terá, na verdade, proferido juízo sobre o mérito da questão" (STJ, 2 ${ }^{\mathrm{a}}$ Turma, REsp. 832.370/MG, Rel. Ministra Nancy Andrighi, j. em 02/08/2007, DJ 13/08/2007).

"[...] se mostra saudável a lembrança de que a doutrina moderna, bem como, em decisões recentes, também o Superior Tribunal de Justiça, têm entendido que o momento de verificação das condições da ação se dá no primeiro contato que o julgador tem com a petição inicial, ou seja, no instante da prolação do juízo de admissibilidade inicial do procedimento. Trata-se da aplicação da teoria da asserção, segundo a qual a análise das condições da ação seria feita à luz das afirmações do demandante contida em sua petição inicial. Assim, basta que seja positivo o juízo inicial de admissibilidade, para que tudo o mais seja decisão de mérito" (STJ, 2 ${ }^{\mathrm{a}}$ Turma, REsp. 879.188/RS, Rel. Ministro Humberto Martins, j. em 21/05/2009, DJE 02/06/2009).

“[...]1. Nos termos da jurisprudência desta Corte, não há preclusão em relação às condições da ação, que devem ser apreciadas ainda que arguidas em sede recursal. 2. A indevida qualificação de defesa de mérito como condição da ação não transforma sua natureza jurídica. 3. O arbitramento e a condenação ao pagamento de honorários advocatícios contratuais são pedidos juridicamente possíveis. Outorgante que se beneficiou dos serviços advocatícios é parte legítima passiva para a ação condenatória. Teoria da asserção, que leva em conta, para verificar as condições da ação, o alegado pela parte na inicial. [...]" (STJ, 4a Turma, REsp. 595.188/RS. Min. Antônio Carlos Ferreira. j. 22/11/2011).

“[...]. 1. Não tendo o autor da ação de reintegração se desincumbido do ônus de provar a posse alegada, o pedido deve ser julgado improcedente e o processo extinto com resolução de mérito" (STJ. REsp 930.336-MG, Rel. Min. Ricardo Villas Bôas Cueva, julgado em 6/2/2014, Informativo 535 do STJ).

${ }^{14}$ BEDAQUE, José R. dos Santos. Efetividade do processo e técnica processual. São Paulo: Malheiros, 2006, p. 250. 
No STF, no STJ, nos TRFs e nos TJs, chegam a ser uma raridade os julgados de carência de ação em que se extingue o processo com exame de mérito, independentemente da fase em que se encontre. A amostragem revela o contrário: Supremo Tribunal Federal: RE 0001887-59.2014.8.07.000/ DF, j. 14/03/2018; RE c/Agravo ARE 030839608.2015.8.24.0038 SC, j. 24/04/2020; Superior Tribunal de Justiça: REsp 1687821 SC 2015/0308903-7; AREsp 1336752 SP 2018/0197251-0, DJ 03/10/2018; Tribunais Regionais Federais: TRF-3, ApCiv 00206015620154039999 SP, j. 09/09/2019; TRF, AC 432290520144019199, j. 15/10/2014; Tribunais de Justiça: TJ-MG, AC: 10342060741168001/MG, j. 11/03/2016; TJ-RS, AC 70063954176, j. em 25/06/2015.

\section{ABORDAGENS DOUTRINÁRIAS ACERCA DA MANUTENÇÃO OU NÃO DAS CONDIÇÕES DA AÇÃO NO SISTEMA PROCESSUAL BRASILEIRO}

A bem da verdade, o debate sobre as condições da ação existe desde longa data, muito antes, portanto, do Código Processual de 2015. Talvez o artigo mais didático e científico sobre esta questão que atormenta os juristas tenha sido aquele escrito por Botelho de Mesquita, em parceria com seus alunos do curso de mestrado em Direito da USP, publicado na Revista de Processo n. 152, em 2007. ${ }^{15}$

Neste ensaio, o saudoso professor Botelho de Mesquita e demais autores, encaminham uma retrospectiva histórica das posições então existente sobre as condições da ação a partir do escólio liebmaniano. O referido estudo revela que os juristas do sul seguiram a linha sustentada pelo professor gaúcho Galeno Lacerda no sentido de que as condições da ação se acomodavam na análise do mérito da lide, entre estes: Ovídio A. Baptista da Silva, Adroaldo Furtado Fabrício, Fábio Gomes e Araken de Assis, e os processualistas do eixo São Paulo - Rio, que seguiam o escólio de Liebman, distinguindo, portanto, condições da ação e mérito. Assim, Alfredo Buzaid, José Frederico Marques, Luiz Eulálio B. Vidigal, Moacyr Amaral Santos, concebendo um juízo prévio de admissibilidade que não é o juízo de mérito, entendido como fundo do litígio ou a pretensão que o autor deduz em juízo por meio do pedido. Estes autores, corifeus de

${ }^{15}$ BOTELHO DE MESQUITA, José Ignácio; LOMBARDI, Mariana C.; AMADEO, Rodolfo C. M. R.; DELLORE, Luiz G. P.; ZVEIBIL, Daniel G. O colapso das condições da ação?: um breve ensaio sobre os efeitos da carência de ação. Revista de Processo. Ano 32, n. 152, out. 2007, p. 11-55. 
Liebman, grosso modo, defendem a separação das matérias postas sob a apreciação do juízo em três planos: pressupostos processuais, condições da ação e mérito da causa. ${ }^{16}$

Não sem controvérsia e resistência, predomina hoje doutrinariamente a coexistência no processo civil de três grandes categorias de sistematização inconfundíveis, mas interrelacionadas: a primeira delas diz respeito à ação (e sua existência), batizada de "condições da ação"; a segunda diz respeito ao processo (e sua existência e validade), chamada "pressupostos processuais"; e a terceira, diz respeito a saber quem tem e quem não tem razão sobre o conflito de interesses levado ao Judiciário para resolução, a qual se convencionou chamar de "mérito". ${ }^{17}$

A partir do Código de Processo Civil de 2015, o debate se acirrou novamente. Vicejam posições que sustentam terem desaparecido as condições da ação no CPC, deslocadas para o âmbito dos pressupostos processuais, como a defendida por Didier Jr., ${ }^{18}$ ao sustentar que o órgão jurisdicional teria ainda a incumbência de analisá-las, mas seriam submetidas ou a exame de mérito (possibilidade jurídica do pedido e legitimação ad causam ordinária) ou de pressupostos processuais (interesse de agir e legitimação extraordinária). E, adotando uma posição contrária, aqueles que se mantém fieis à tradição processual defendendo a manutenção implícita das condições da ação, como Nery Jr., ${ }^{19}$ para quem se faz necessária, não só para propor, mas também para ter direito a uma sentença de mérito, a presença das condições da ação. No mesmo sentido, Assumpção Neves ${ }^{20}$ encontra dificuldade para o enquadramento da legitimidade e do interesse de agir no conceito de pressupostos processuais. Tesheiner e Thamay também identificam

${ }^{16}$ BOTELHO DE MESQUITA, José Ignácio; LOMBARDI, Mariana C.; AMADEO, Rodolfo C. M. R.; DELLORE, Luiz G. P.; ZVEIBIL, Daniel G. O colapso das condições da ação?: um breve ensaio sobre os efeitos da carência de ação. Revista de Processo. Ano 32, n. 152, out. 2007, p. 13-23.

${ }^{17}$ Por todos, BUENO, Cassio Scarpinella. Curso Sistematizado de Direito Processual Civil. Vol. I. 3. ed. São Paulo. Saraiva, 2009, p. 362.

${ }^{18}$ DIDIER JR., Fredie. Será o fim da categoria "condição da ação"? Um elogio ao projeto do novo CPC. Disponível em: http://www.frediedidier.com.br/wp-content/uploads/2012/06/Condi\%C3\%A7\%C3\%B5es-daa\%C3\%A7\%C3\%A3o-e-o-projeto-de-novo-CPC.pdf. Acesso em: 19 maio 2020.

${ }^{19}$ NERY JR, Nelson. Código de Processo Civil comentado [livro eletrônico] 3. ed. São Paulo: Thomson Reuters Brasil, 2018, p. 108-109.

20 NEVES, Daniel Amorim Assumpção. Manual de Direito Processual Civil. 10. ed. - Salvador: JusPODIVM, 2018, p. 129. 
impropriedade na provável confusão entre ação e processo, caso extintas as condições da ação. ${ }^{21}$

Arauto da posição que sustenta terem desaparecido as condições da ação, Didier defende que, além da modificação visível operada no novo Código de Processo Civil - no tocante ao deslocamento da impossibilidade jurídica do pedido para o juízo meritório -, houve a alteração silenciosa de consagração do interesse e da legitimidade como integrantes "[...] do repertório teórico dos pressupostos processuais". 22

Ao demonstrar este novo paradigma, considerado pelo autor como mais adequado do que o anterior, que não relacionava a impossibilidade jurídica do pedido ao juízo meritório, defendeu também a ideia de eliminação de análise intermediária entre o juízo de admissibilidade e o de mérito: precisamente onde se encontram as condições da ação. Assim, a legitimidade e o interesse processual se alocariam em um ou outro.

Para Didier, a análise meritória se ocuparia com os casos de ausência de legitimação ordinária, implicando a improcedência do pedido caso o autor não fosse legitimado para perquirir a tutela pleiteada. A falta de legitimação ordinária equivaleria à ausência de titularidade do direito afirmado e seria, assim, um pressuposto para o acolhimento da pretensão, uma questão de mérito, e não de admissibilidade, conquanto a legitimação extraordinária seja compreendida como pressuposto processual. $^{23}$

Há a defesa, portanto, da extinção das condições da ação como conceito, mas a legitimidade, o interesse e a possibilidade jurídica do pedido encontrar-se-iam ainda presentes, porém em uma divisão mais simplista - juízo de admissibilidade ou de mérito. Para a alocação em um ou outro conceito, deveriam ser consideradas outras questões, como as características de ordinária ou extraordinária a que a legitimação se reveste.

\footnotetext{
${ }^{21}$ Isso porque os autores sustentam ser a ação uma coisa e processo outra. Nesse tocante, "Permanece a categoria das condições da ação, porque permanece a exigência de interesse e legitimidade para a propositura de ação". TESHEINER, José Maria Rosa; THAMAY, Rennan Faria Krüger. Condições da ação no novo CPC. 2017. Disponível em: http://www.rkladvocacia.com/condicoes-da-acao-no-novo-cpc/. Acesso em: 20 de maio 2020.

${ }^{22}$ DIDIER JR., Fredie. Será o fim da categoria “condição da ação”? Um elogio ao projeto do novo CPC. Disponível em: http://www.frediedidier.com.br/wp-content/uploads/2012/06/Condi\%C3\%A7\%C3\%B5es-daa\%C3\%A7\%C3\%A3o-e-o-projeto-de-novo-CPC.pdf. Acesso em: 19 maio 2020.

${ }^{23}$ DIDIER JR., Fredie. Será o fim da categoria "condição da ação"? Um elogio ao projeto do novo CPC. Disponível em: http://www.frediedidier.com.br/wp-content/uploads/2012/06/Condi\%C3\%A7\%C3\%B5es-daa\%C3\%A7\%C3\%A3o-e-o-projeto-de-novo-CPC.pdf. Acesso em: 19 maio 2020.
} 
Na linha oposta de pensamento, encontrar-se o professor Alexandre Freitas Câmara, sustentando que antes de prover sobre o mérito, "é preciso que o Estado-juiz verifique a presença de uma série de requisitos, os quais poderiam, genericamente, ser chamados de "requisitos de admissibilidade do provimento de mérito", ${ }^{24}$ consoante antigo escólio de Alfredo Buzaid assim vazado:

Para que o juiz possa chegar ao termo último da ação e proferir sentença definitiva, é preciso que concorram, na formação e desenvolvimento do processo, várias condições, que denominamos de condições de admissibilidade do julgamento da lide. Com esta expressão designamos todas as condições necessárias para que o juiz possa conhecer do mérito da causa e decidir o conflito de interesse, dando razão a uma das partes e negando-a à outra. Não são condições de uma sentença qualquer, mas sim condições de uma sentença de mérito. Pode-se dividir, pois, todo o material que se apresenta ao conhecimento do Juiz em duas categorias fundamentais: de um lado, a lide; do outro lado, as condições de admissibilidade da lide. Concorrendo estas condições, o juiz julgará a lide; mas faltando alguma delas, o juiz proferirá uma sentença que implica a terminação do processo, sem lhe resolver o mérito. Estas condições de admissibilidade do julgamento da lide são variadas, heterogêneas e independentes entre si..$^{25}$

\section{NOSSA POSIÇÃO SOBRE AS CONDIÇÕES DA AÇÃO}

Diante das hipóteses levantadas, doravante impende definir, justificadamente, nossa compreensão acerca das condições da ação.

Primeiro de tudo, é preciso dizer que a exclusão da (im)possibilidade jurídica do elenco das condições da ação (o art. 17 do CPC refere apenas a legitimidade o interesse de agir), foi medida acertada. O próprio Liebman, depois da $3^{\text {a }}$ edição do seu Manuale, com a aprovação do divórcio na Itália, sustentou a desnecessidade da possibilidade jurídica do pedido como condição da ação, propondo o seu deslocamento para o âmbito do interesse de agir, reescrevendo, de certo modo, a sua teoria eclética. ${ }^{26}$

Já se disse que as condições da ação dizem respeito ao exercício do direito subjetivo público de agir, de provocar a atuação do Judiciário caracterizada pela inércia. Em princípio tal análise (da legitimidade e do interesse de agir) deve preexistir

${ }^{24}$ CÂMARA, Alexandre Freitas. Será o fim da categoria "Condição da Ação"? Uma resposta a Fredie Didier Junior. Disponível em: <https://www.leonardocarneirodacunha.com.br/artigos/sera-o-fim-dacategoria-condicao-da-acao-uma-resposta-a-fredie-didier-junior/> Acesso em: 10 de junho 2020.

${ }^{25}$ BUZAID, Alfredo. Do agravo de petição no sistema do Código de Processo Civil. 2. ed. - São Paulo: Saraiva, 1956, p. 115-116.

${ }^{26}$ LIEBMAN, Enrico Tullio. Manuale di Diritto Processuale Civile. 5. ed. - Milão. Giuffrè, 1992, p. 144. 
naturalmente ao preenchimento dos pressupostos processuais, que dizem respeito à existência e à validade do processo, enquanto instrumento do atuar jurisdicional (capacidade de ser parte, de agir, postulatória, ausência de litispendência, coisa julgada etc).

Pode parecer, a partir desta assertiva, que somente se deve considerar as condições, como tal, no início do processo. Ocorre que não existe uma "ordem de precedência", "muito menos uma ordem rígida entre o exame do preenchimento das condições da ação e dos pressupostos processuais em cada caso concreto". ${ }^{27}$ Não é o momento da análise e do reconhecimento que definem a categoria processual.

No início do processo, a análise da inicial enseja o exame conjunto de ambos: condições da ação e pressupostos processuais. Superada esta fase, e em todo curso do processo, exerce o juiz o controle tanto de umas como de outros. Reconhecida a ausência de condições da ação em momento processual mais adiantado, e mesmo depois da sentença e em grau recursal (em qualquer tempo e grau de jurisdição, a rigor), tal enfrentamento não deixará de ser de carência de ação, com extinção sem exame de mérito.

É fácil perceber que, a partir do reconhecimento de que as condições da ação devem ser analisadas somente no início do processo, passando todo o mais a constituir mérito depois desta fase postulatória, persistem as fronteiras entre a carência de ação e o julgamento de mérito (improcedência) desprovidas de uma racionalidade científica, ficando, inclusive, sem uma explicação razoável a hipótese da carência de ação diante do perecimento superveniente do interesse de agir ou da legitimação para a causa, ambas situações comumente ocorrentes na práxis pretoriana.

Ao que se pensa, quem melhor refutou os argumentos da corrente assercionista foi Botelho de Mesquita, no artigo já citado, e o fez por meio de exemplos práticos em que demonstrou ser perfeitamente possível conferir autonomia às condições da ação, separando o juízo de admissibilidade do mérito do pedido propriamente dito, isolando do mérito da causa as condições da ação. Para esta tarefa, impõe-se observar que o mérito da causa é $a$

${ }^{27}$ BUENO, Cassio Scarpinella. Curso Sistematizado de Direito Processual Civil. Vol. I. 3. ed. - São Paulo: Saraiva, 2009, p. 363. 
relação existente entre o pedido e a causa de pedir. "Decisão de mérito é a que o juiz pronuncia sobre a relação existente entre o pedido e a causa de pedir". ${ }^{28}$

Ao contrário, tendo-se presente que o juízo de mérito é um juízo sobre a relação entre o objeto do pedido e a causa de pedir, torna-se facilmente compreensível que uma sentença que julgue impossível o pedido isoladamente considerado não decida o mérito da causa e que são completamente distintas neste caso as hipóteses de carência e improcedência da ação. As sentenças de carência por impossibilidade jurídica do pedido e as de improcedência por falta de fundamento jurídico para o pedido têm objetos inteiramente diferentes: a primeira se pronuncia sobre o pedido e a segunda sobre a relação entre o pedido e a causa de pedir. ${ }^{29}$

Em relação às demais condições da ação, vale a mesma premissa. Botelho de Mesquita (et al) mostra que é possível um juízo de admissibilidade em relação à legitimatio ad causam e o interesse de agir e um juízo de mérito (diverso) que incide sobre a relação entre o fundamento e o objeto do pedido, trazendo a tona exemplos elucidativos, que os limites deste ensaio não permitem referir. ${ }^{30}$

A práxis pretoriana convive tranquilamente com situações tais em que apenas se examina a pertinência do réu em relação direito vindicado, sem adentrar o mérito (relação entre o pedido e a causa de pedir):

PROCESSO CIVIL. REMESSA OFICIAL. EMBARGOS DE TERCEIRO. AUSÊNCIA DE COMPROVAÇÃO DE PROPRIEDADE DO VEÍCULO.

\footnotetext{
${ }^{28}$ Um deles é o da ação reivindicatória que seja proposta por quem se declara primo do proprietário ou simples possuidor direto da coisa demandada, cujo uso lhe fora cedido pelo respectivo proprietário, a título de locação ou comodato. A sentença que extinguir o processo, o fará sem exame de mérito, porque nada dirá sobre se, no caso, existiria, ou não, o direito de propriedade e se o réu estaria, ou não, possuindo injustamente o imóvel de que não é proprietário. Uma típica questão de legitimidade para a causa. BOTELHO DE MESQUITA, José Ignácio; LOMBARDI, Mariana C.; AMADEO, Rodolfo C. M. R.; DELLORE, Luiz G. P.; ZVEIBIL, Daniel G. O colapso das condições da ação?: um breve ensaio sobre os efeitos da carência de ação. Revista de Processo. Ano 32, n. 152, out. 2007, p. 23.

${ }^{29}$ BOTELHO DE MESQUITA, José Ignácio; LOMBARDI, Mariana C.; AMADEO, Rodolfo C. M. R.; DELLORE, Luiz G. P.; ZVEIBIL, Daniel G. O colapso das condições da ação?: um breve ensaio sobre os efeitos da carência de ação. Revista de Processo, Ano 32, n. 152, out. 2007, p. 23.

30 BOTELHO DE MESQUITA, José Ignácio; LOMBARDI, Mariana C.; AMADEO, Rodolfo C. M. R.; DELLORE, Luiz G. P.; ZVEIBIL, Daniel G. O colapso das condições da ação?: um breve ensaio sobre os efeitos da carência de ação. Revista de Processo, Ano 32, n. 152, out. 2007, p. 23-28.
} 
CARÊNCIA DA AÇÃO. INVERSÃO DO ÔNUS DE SUCUMBÊNCIA. 1. O art. 1.267 do $\mathrm{CC} / 2002$ assevera que "a propriedade das coisas não se transfere pelos negócios jurídicos antes da tradição", de modo que a transferência da propriedade do veículo ocorre pela tradição e não pelo registro junto ao DETRAN. 2. O embargante afirma ser o legítimo proprietário do veículo discutido nos autos. Ausência de demonstração tal qualidade. 3. Sentença reformada para reconhecer sua ilegitimidade passiva ad causam. Inteligência do art. 485, inciso VI, do CPC/15. 4. Remessa oficial provida (TRF-3, $6{ }^{\text {a }}$ Turma, REO: 00026369620094036112 SP, Relatora Des. Federal Consuelo Yoshida, j. em 20/10/2016).

Ementa: COBRANÇA DE DÉBITOS CONDOMINIAIS ILEGITIMIDADE PASSIVA SUPERVENIENTE. Condomínio que desconhecia a existência de compromisso particular de compra e venda da unidade devedora e ajuizou ação de cobrança de débitos condominiais contra a antiga proprietária, cujo nome ainda constava no registro imobiliário. Pagamento integral do débito efetuado por terceiro. Ilegitimidade passiva superveniente caracterizada, porque somente foi conhecida com o curso da demanda, e que motivou a extinção do feito sem resolução do mérito. Recurso provido (Tribunal de Justiça de São Paulo, Apelação APL 00273074320108260562/SP, j. 05/02/2013).

Fixadas estas premissas epistemológicas, a posição que se adota, conquanto se entenda que a novel codificação poderia ter poupado os atores jurídicos do esforço hermenêutico, referindo expressamente estar tratando de condições da ação ao falar da legitimidade e do interesse de agir, vai no sentido de admitir como inequívoca a manutenção das condições da ação. Não só por uma opção manifesta nos incisos V e VI do art. 485, um cuidando de pressupostos e outro das condições da ação, desvanecendo a tese dos que sustentam que tudo agora é pressuposto processual, mas, sobretudo, porque não se pode confundir, as condições da ação, relacionadas com o direito subjetivo de agir em juízo perante a situação de direito material, com os pressupostos processuais, destinados que são a garantir a constituição e o desenvolvimento válidos do "processo".

É defeso, pois, por simples amor a uma perspectiva de cunho instrumental e utilitarista, em sacrifício de categorias processuais consolidadas, afirmar-se que ambas seriam "faces de uma mesma moeda".

Assente, do ponto de vista doutrinário e jurisprudencial, que pressupostos processuais e condições da ação são categorias processuais diversas e inconfundíveis, em sua teoria, elementos, objetivos e momento de exame, ${ }^{31}$ uma observação sistêmica, mostra

${ }^{31}$ ALVIM, José Manuel. Condições da ação no processo civil contemporâneo: enfoque sobre o interesse de agir no direito processual civil brasileiro. 40 anos de teoria geral do processo no Brasil, p. 60-61. In: Enciclopédia Jurídica da PUCSP, Tomo III (recurso eletrônico): processo civil. Coords. Cássio Scarpinella 
que andou bem o Código ao determinar que a sua ausência conduz à extinção do processo, sem resolução de mérito, alocando-os, cada um de per si, em diferentes incisos: quando se verificar a ausência de pressupostos de constituição e de desenvolvimento válido e regular do processo (art. 485, inciso IV), e ausência de legitimidade para a causa de interesse de agir (art. 485, inciso VI). É uma opção de lógica, e a prova cabal de que as condições da ação, embora escoimadas da possibilidade jurídica do pedido, se mantêm hígidas no regime processual brasileiro.

Processualistas de renome testemunham que as condições da ação não foram expurgadas do sistema processual brasileiro. Destaca-se adiante o pensamento de alguns deles.

Fabio Caldas de Araújo explica que a "eliminação da expressão "carência de ação" pouco importa, uma vez que as categorias do interesse e da legitimidade permanecem expressas no art. 17 ". 32

José M. R. Tesheiner e Rennan Thamay sustentam que

enquadrar a legitimidade e o interesse entre os pressupostos processuais implica confundir ação com processo e não se pode pura e simplesmente negar a existência das condições da ação, por implicar negação do que a lei afirma: a necessidade de interesse e legitimidade para a postulação em juízo. ${ }^{33}$

Eduardo Cambi (et al.) refere que segundo o novo diploma processual brasileiro, "são então apenas duas as condições da ação: legitimidade para a causa e interesse de agir (CPC, art. 17). Na ausência desses requisitos, o processo deve ser extinto sem julgamento de mérito (CPC, art. 485, VI)". ${ }^{34}$

Se o Código novo não aludiu mais ao nominem iuris "condições da ação", as manteve, indubitavelmente, no conteúdo e na essência. $\mathrm{O}$ dado relevante e com

Bueno e Olavo de Oliveira Neto - São Paulo: Pontifícia Universidade Católica de São Paulo, 2017, p. 4; CÂMARA, Alexandre Freitas. Será o fim da categoria "Condição da Ação"? Uma resposta a Fredie Didier Junior. Disponível em: https://www.leonardocarneirodacunha.com.br/artigos/sera-o-fim-da-categoriacondicao-da-acao-uma-resposta-a-fredie-didier-junior/> Acesso em: 10 de junho 2020.

32 ARAÚJO, Fábio Caldas de. Curso de Processo Civil. Tomo I, Parte Geral. São Paulo: Malheiros, 2016, p. 349.

${ }^{33}$ TESHEINER, José Maria Rosa;THAMAY, Rennan Faria Krüger. Condições da ação no novo CPC. 2017. Disponível em: 〈http://www.rkladvocacia.com/condicoes-da-acao-no-novo-cpc/>. Acesso em: 20 de maio 2020.

${ }^{34}$ CAMBI, Eduardo et al. Curso de Processo Civil. São Paulo: RT, 2017, p. 97. No mesmo sentido, Leonardo Faria Schenk, na obra coletiva coordenada por WAMBIER, Teresa Arruda Alvim (et al.). Breves Comentários ao novo Código de Processo Civil. São Paulo: Thomson Reuters RT, 2015. 
sensibilidade pragmática é que, independentemente das alegações, da existência de instrução probatória, descoberta a carência de ação, a extinção persiste sendo sem exame de mérito.

Na prática, a tendência aponta no sentido de que os tribunais, devido à intrínseca similitude entre as condições da ação e o mérito, não deverão observar a tênue, e às vezes imperceptível, diferença entre interesse secundário e instrumental (relacionado com o direito de ação) e o interesse primário substancial, que autoriza o juiz a julgar o mérito da demanda, entre uma legitimação ordinária e extraordinária, e continuarão julgando como sempre julgaram, vale dizer, segundo um misto de provocação, momento e matéria, ora com, ora sem exame de mérito.

Não se pode esquecer que de forma oblíqua, a teoria eclética conspirou favoravelmente, em razão da imbricação autonomista-concretista, para a superação do divórcio entre o direito material e o processo, cujos nexos somente agora estão sendo redescobertos, depois de anos encobertos pela aclamada autonomia da ação e da relação processual. Portanto, não se pode abandonar o debate e sua evolução e construções, em que pesem as antinomias, que, aliás, a práxis sempre cuidou de corrigir.

O que muda, então? Mais do que nunca, é o conteúdo da decisão que vai ditar o regime da coisa julgada e da possibilidade de propositura da Ação Rescisória, conforme adiante será examinado, a partir de uma análise sistêmica em que os institutos e categorias processuais demandam um olhar integrado.

\section{CONDIÇÕES DA AÇÃO E COISA JULGADA NO CPC}

Perpassado o exame das condições da ação e sua presença como elemento do trinômio da análise processual, necessária se faz a conexão entre estas e o disposto no artigo 486, § $1^{\circ}$, do Código de Processo Civil, que traz a possibilidade da propositura de nova ação mediante a correção do vício que levou à sentença sem resolução de mérito, quando constatada a ausência de legitimidade ou de interesse de agir.

De acordo com o art. 486, caput, do novo CPC, "o pronunciamento judicial que não resolve o mérito não obsta a que a parte proponha de novo a ação”, mas estabelece pressupostos formais para o ajuizamento de nova ação $\left(\S \S 2^{\circ}\right.$ e $\left.3^{\circ}\right)$ : pagamento das custas e honorários e não ter provocado três extinções por abandono da causa. Superou-se o mito de 
que as sentenças terminativas - e a imutabilidade que lhes é conferida com o trânsito em julgado - não podem gerar efeitos extraprocessuais.

Para Antonio dos Passos Cabral, com quem anuímos, no sistema do novo CPC, as decisões que encerram o processo, impedindo a análise do mérito por razões processuais, mesmo não produzindo o fenômeno da coisa julgada, conforme dicção do art. 502, são protegidas por outra espécie de estabilidade. Trata-se de uma preclusão extraprocessual que estabelece uma força prima facie em favor da manutenção do conteúdo estável, e exige, para sua alteração, que surjam novos elementos fáticos ou jurídicos aptos a modificar a conclusão anterior. ${ }^{35}$

Já se disse que o STJ havia aderido à teoria da asserção, segundo o entendimento de que a análise das condições da ação deve ser feita à luz das afirmações do demandante contida em sua petição inicial. "Assim, basta que seja positivo o juízo inicial de admissibilidade, para que tudo o mais seja decisão de mérito" (STJ, 2a Turma, REsp. 879.188/RS, Rel.: Ministro Humberto Martins, j. em 21/05/2009, DJE 02/06/2009).

Ocorre que este entendimento, à luz do art. 485, VI, considerando que a possibilidade jurídica não foi mantida como instituto autônomo, seja porque se compreende no interesse de agir, seja porque está muito mais relacionada com o mérito da demanda, por uma ou por outra, não mais se justifica enquadrar a falta de condições da ação, vale dizer, a carência da ação, como julgamento de mérito, não se tratando de hipótese contemplada no art. 487 do CPC.

Tal prática, que traduz a confusão entre direito de ação e o mérito da ação, implica sonegar à parte contra quem é proferida a sentença de mérito o direito de propor novamente a ação, rompendo a estabilidade das decisões processuais diante do surgimento de fato ou direito novos, nos termos do art. 486, antes citado, porque a sentença de mérito se submete à coisa julgada material, ficando a questão decidida imutável e indiscutível (arts. 502 e 503 do CPC).

35 CABRAL, Antonio dos Passos. Breves comentários ao novo Código de Processo Civil, Disponível em: https://edisciplinas.usp.br/pluginfile.php/4231064/mod_resource/content/1/Antonio\%20do\%20Passo\%20Cab ral\%20-\%20Comentario\%20arts. $\% 20502 \% 20 \mathrm{a} \% 20508 \% 20-\% 20$ Breves\%20Comentarios.pdf. Acesso em: 20 jul. 2020. 
Alguém diria que nenhuma utilidade há em se defender a inexistência da coisa julgada material, na medida em que, para a propositura da ação novamente, seria necessário corrigir o vício que levou à extinção da anterior por carência de ação. Os vícios de ilegitimidade para a causa e falta de interesse de agir não poderiam ser sanados a não ser com o ajuizamento de outra ação (com elementos diversos: partes ou causa de pedir), não sendo esta alcançada pela coisa julgada material.

Não podemos subestimar a práxis e sua riqueza de possibilidades. Uma hipótese recorrente e bem conhecida é a extinção do processo por carência de ação porque não se produz a prova que poderia demonstrar a condição de proprietário ou mesmo a resistência indevida do réu caracterizadora da lide.

Mas, se dão também outras situações. Uma delas é a mudança do quadro fático ou jurídico, que, sem representar uma alteração nos elementos da ação (a ação persiste sendo a mesma), desafia o interesse em propor novamente a ação, como autoriza o art. 486 do CPC.

Respondendo a esta mesma pergunta, o professor Botelho de Mesquita (et al) diz:

Esta hipótese existe. É o caso em que, depois do trânsito em julgado da sentença de carência de ação, sobrevém alteração no direito positivo que torne juridicamente possível o pedido, ou que confira legitimação para a parte, ou que, tornando necessária a via judicial, crie o interesse de agir. ${ }^{36}$

E arremata o saudoso professor: "A nova ação, nestes casos, será idêntica à anterior, porque continuarão inalterados tanto as partes, como o pedido e a causa de pedir". 37

O princípio do due process of law, em seu viés adjetivo (procedural due process), representa que as partes em juízo têm direito subjetivo ao procedimento disposto na lei (legalidade), vale frisar, ao procedimento previamente estabelecido pelo legislador, não podendo o juiz ou o tribunal alterar a forma da prática de um ato processual (sentença), quando a alteração é prejudicial a uma das partes.

${ }^{36}$ BOTELHO DE MESQUITA, José Ignácio; LOMBARDI, Mariana C.; AMADEO, Rodolfo C. M. R.; DELLORE, Luiz G. P.; ZVEIBIL, Daniel G. O colapso das condições da ação?: um breve ensaio sobre os efeitos da carência de ação. Revista de Processo, Ano 32, n. 152, out. 2007, p. 30-31.

37 BOTELHO DE MESQUITA, José Ignácio; LOMBARDI, Mariana C.; AMADEO, Rodolfo C. M. R.; DELLORE, Luiz G. P.; ZVEIBIL, Daniel G. O colapso das condições da ação?: um breve ensaio sobre os efeitos da carência de ação. Revista de Processo, Ano 32, n. 152, out. 2007, p. 31. 
Assim, independentemente do momento em que a ausência de condições da ação é constatada (e este juízo pode ocorrer a qualquer tempo e grau de jurisdição: no juízo de admissibilidade, depois da instrução, depois da sentença e em grau recursal, de ofício ou mediante alegação), não deixará ser de um juízo de carência de ação, e, destarte, decisão terminativa, e não definitiva.

\section{CONDIÇÕES DA AÇÃO E AÇÃO RESCISÓRIA}

Outro corolário da natureza terminativa (sem exame de mérito) do juízo de carência de ação, diz respeito à impossibilidade do ajuizamento de Ação Rescisória contra essa decisão. Conquanto o CPC de 2015 tenha aberto exceção para permitir a rescindibilidade de decisões que extinguem o processo sem exame de mérito, o fez, no $\S 2^{\circ}$ do art. 966 , apenas em duas hipóteses, a saber: (I) quando a decisão impedir nova propositura da demanda ou (II) a admissibilidade do recurso correspondente.

Fosse a extinção do processo com exame de mérito, caberia a Ação Rescisória. Neste ponto, ao que nos parece, não andou bem o novo CPC, pois permite a sanabilidade do vício no caso de carência de ação, e a nova propositura da mesma demanda, porém em uma hipótese em que a correção do vício é quase sempre impossível.

Sendo definitiva a sentença, não fará coisa julgada material, embora, como dito, hodiernamente, possa estabilizar-se. A falta de legitimidade para a causa e do interesse de agir, todavia, na prática, dificilmente poderá ser suprida. Melhor dizendo, nada obstante sejam vícios supríveis ao modo de autorizar que a mesma ação seja (re)proposta após corrigido o vício que levou à extinção por carência de ação, essa possibilidade é bem restrita.

Não se despreza, como já se disse, a probabilidade de alguém provar sua legitimidade ou interesse de agir antes não reconhecidos, mas isso demandaria um esforço que corresponde justamente àquele empregado nas hipóteses que constituem fundamentos para a propositura da Ação Rescisória, como, por exemplo: prevaricação, concussão ou corrupção do juiz, impedimento ou incompetência, dolo, coação, simulação ou colusão, coisa julgada, prova falsa ou nova e erro de fato. 
Assim, parece-nos que a hipótese de carência de ação, seja por falta de interesse, seja por ilegitimidade ad causam, remanesce em verdadeiro limbo. Remotamente pode haver sanabilidade do vício e, ao mesmo tempo, não admite a Ação Rescisória, por não se enquadrar nas hipóteses legais numerus clausus de rescindibilidade no caso de decisões que não examinam o mérito.

O professor Flávio L. Yarshell ensina que caberá ação rescisória contra decisão terminativa que, conquanto permita, abstratamente, a propositura de nova demanda, por se revelar gravemente equivocada, acabe por não ensejar, na prática, a superação do vício que a motivou pela parte que pretende repropor a ação. Ainda que o referido processualista aludisse ao caso da litispendência, seu escólio vale para qualquer hipótese em que não seja possível corrigir o erro, mas também quando a decisão extintiva venha a encerrar grave equívoco. Explica o autor:

Sem embargo do presumido (e louvável) objetivo do Legislador, perdeu-se a oportunidade de evitar ou de superar controvérsias. Quanto à litispendência, a premissa do Legislador foi a de que o vício seria sanável quiçá pela demonstração de que se extinguiu (sem resolução do mérito) o processo cuja pendência era impeditiva de um segundo com idênticos elementos identificadores. Mas, essa possibilidade de repropor a demanda não afasta o cabimento da rescisória: é possível que, justamente por estar gravemente equivocada, a decisão que extinguiu o processo por litispendência não possa ensejar qualquer superação de vício. Então, se a decisão que afirmou a litispendência está maculada por vícios do art. 966, o correto será rescindi-la; e não propor uma nova demanda na expectativa de se corrigir o que não pode ser corrigido (o que precisa ser corrigida é a decisão, não a petição inicial).[...] (grifo nosso). ${ }^{38}$

\section{CONCLUSÕES}

As condições da ação, conforme previstas no Código de Processo Civil de 1973, ganharam contornos distintos no novo diploma processual. Apesar das dúvidas suscitadas, conclui-se que permanecem hígidas, restando na supramencionada categoria composta pelo interesse de agir e pela legitimatio ad causam. A (im)possibilidade jurídica do pedido, como havia proposto Liebman, passou compor o interesse de agir. Pode-se afirmar que o novo CPC, assim como o de 1973, manteve-se fiel à Teoria Eclética de Enrico T. Liebman.

${ }^{38}$ YARSHELL, Flávio Luiz. Breves Notas sobre a Disciplina da Ação Rescisória no CPC 2015. In: BONATO, Giovanni (Coord.). O Novo Código de Processo Civil: Questões Controvertidas. São Paulo: Atlas, 2015. 
Sendo inegável a relevância de ambos para que possa haver a tutela jurisdicional do caso concreto, e tendo sido tratados como condições de admissibilidade de um julgamento de mérito, bem como alocadas, no art. 485, em inciso diferente do relativo aos pressupostos processuais, conclui-se que ambos continuam sendo condições da ação. Assim, consoante a doutrina majoritária, estas permanecem - ainda que veladamente - no novo Código de Processo Civil, respeitando-se a tradição do direito sufragada na doutrina, que há muito tempo atrás separou o direito de ação do direito ao processo, instituindo, com finalidades diversas, as condições da ação e os pressupostos processuais.

Admitindo a manutenção das condições da ação no novo Código de Processo Civil, outros questionamentos são suscitados acerca do momento e da natureza do provimento judicial que declara a carência de ação, dada a implicação na práxis judicial e na consequente formação ou não de coisa julgada material.

Nesse viés, não se admite que as condições da ação se limitem a uma fase processual, ficando adstritas ao que o autor alega em seu petitório inicial, in statu assertionis. É com o desenrolar dos atos processuais que muitas vezes se percebe a ausência delas - pressuposto deflagrador da provocação do autor para que corrija o vício, ou posteriormente para que haja a extinção do processo por carência de ação. Não é, pois, o momento da análise, nem a profundidade da cognição, que definem a natureza da decisão judicial. É a categoria processual que determina o tipo de decisão judicial a ser exarada com ou sem mérito -, em uma fase ou em outra. Portanto, conclui-se que as condições da ação podem ser analisadas em qualquer fase processual. Bem disse o professor Paulo H. S. Lucon, "as condições da ação não são resultantes da mera alegação do demandante, mas da situação substancial trazida a julgamento".39

No que tange ao tipo de extinção ao qual é submetido o processo ausentes as condições da ação (terminativa ou definitiva), relacionando-se à coisa julgada (formal ou material), deve-se considerar que as partes têm direito subjetivo ao procedimento disposto em lei, conforme o princípio do Due Process of Law em seu viés procedural, enquanto

\footnotetext{
${ }^{39}$ LUCON, Paulo Henrique dos Santos. Novas tendências na estrutura fundamental do processo civil. Revista do Advogado, no 88, nov. 2006, p. 152.
} 
garantia fundamental dos litigantes. E, a propósito, há expressa disposição legal dizendo que a extinção do processo se dará sem exame de mérito (art. 485, VI, CPC).

Ao enquadrar as condições da ação como matéria meritória, conforme sustenta a teoria assercionista, caso improcedente - e fazendo coisa julgada material -, a possibilidade conferida ao autor seria unicamente socorrer-se da Ação Rescisória, via angusta de natureza decadencial e condicionada a pressupostos taxativos.

Esta posição sistêmica que se sustenta está coadunada com os direitos e garantias fundamentais do litigante do processo e com o princípio da efetividade, pois, sem implicar esgarçamento de categorias processuais seculares ou elastecimento do rito, mantém íntegros outros direitos correlatos da carência de ação, como é a propositura de nova ação.

\section{REFERÊNCIAS}

ALVIM, José Manuel. Condições da ação no processo civil contemporâneo: enfoque sobre o interesse de agir no direito processual civil brasileiro. 40 anos de teoria geral do processo no Brasil. In: BUENO, Cássio Scarpinella; NETO, Olavo de Oliveira (Coords.) Enciclopédia Jurídica da PUC/SP, Tomo III (recurso eletrônico): processo civil. - São Paulo: Pontifícia Universidade Católica de São Paulo, 2017, p. 60-61.

ARAÚJO, Fábio Caldas de. Curso de Processo Civil. Tomo I, Parte Geral. São Paulo: Malheiros, 2016.

BEDAQUE, José R. dos Santos. Efetividade do processo e técnica processual. São Paulo: Malheiros, 2006.

BOTELHO DE MESQUITA, José Ignácio; LOMBARDI, Mariana C.; AMADEO, Rodolfo C. M. R.; DELlORE, Luiz G. P.; ZVEIBIL, Daniel G. O colapso das condições da ação?: um breve ensaio sobre os efeitos da carência de ação. Revista de Processo. Ano 32, n. 152, out. 2007, p. 11-55.

BUENO, Cassio Scarpinella. Curso Sistematizado de Direito Processual Civil. Vol. I. 3. ed. - São Paulo. Saraiva, 2009.

BUZAID, Alfredo. 2. ed. - São Paulo: Saraiva. 1956.

CABRAL, Antonio dos Passos. Breves comentários ao novo Código de Processo Civil, Disponível em: 
https://edisciplinas.usp.br/pluginfile.php/4231064/mod_resource/content/1/Antonio\% 20do\%20Passo\%20Cabral\%20-\%20Comentario\%20arts.\%20502\%20a\%20508\%20-

\%20Breves\%20Comentarios.pdf. Acesso em: 20 jul. 2020.

CALAMANDREI, Piero. Istituzioni di diritto processuale civile. Pádua: Cedam, 1943.

CALMON DE PASSOS, J. J. A Ação no Direito Processual Civil Brasileiro. Livraria Progresso Editora, 1961.

CÂMARA, Alexandre Freitas. O Novo Processo Civil Brasileiro. 1. ed. - Rio de Janeiro: Atlas. 2015.

. Será o fim da categoria "Condição da Ação"? Uma resposta a Fredie Didier Junior. Disponível em: <https://www.leonardocarneirodacunha.com.br/artigos/serao-fim-da-categoria-condicao-da-acao-uma-resposta-a-fredie-didier-junior/> Acesso em: 10 de junho 2020.

CAMBI, Eduardo (et al). Curso de Processo Civil. São Paulo: RT, 2017.

CHIOVENDA, Giuseppe. La acción en el sistema de los derechos. Trad. Santiago Sentís Melendo. Valparaíso (Chile): Edeval, 1992.

CINTRA, Antônio Carlos Araújo; DINAMARCO, Cândido Rangel; GRINOVER, Ada Pellegrini. Teoria geral do processo. 7. ed. - São Paulo: RT, 1990.

COUTURE, Eduardo. Introducción al Estudio Del Proceso Civil. Buenos Aires: Editorial Depalma, 1949.

DIDIER JR., Fredie. Curso de Direito Processual Civil. V.1. Ed. JusPodivm, 2017. Um réquiem às condições da ação: estudo analítico sobre a existência do instituto. Disponível em: http://www.juspodivm.com.br/i/a/\%7B090C3970-2C5E-423E-9D1926ECDDC04872\%7D_028.pdf. Acesso em: 02 jun 2020.

. Será o fim da categoria "condição da ação"? Um elogio ao projeto do novo CPC. Disponível em: http://www.frediedidier.com.br/wpcontent/uploads/2012/06/Condi\%C3\%A7\%C3\%B5es-da-a\%C3\%A7\%C3\%A3o-e-oprojeto-de-novo-CPC.pdf. Acesso em: 19 maio 2020.

DINAMARCO, Cândido Rangel. Reflexões sôbre direito e processo. https://revistas.ufpr.br/direito/article/viewFile/7193/5148. Acesso em 20 jul. 2020. LACERDA, Galeno. Despacho saneador. Porto Alegre: Sérgio Antonio Fabris, 1985. 
LIEBMAN, Enrico Tullio. Manuale di Diritto Processuale Civile. 5. ed. Milão. Giuffrè, 1992.

LIEBMAN, Enrico Tullio. Manual de Direito Processual Civil. Trad. e notas de Cândido

R. Dinamarco. 2. ed. Rio de Janeiro: Forense, 1985 (v. 1).

LUCON, Paulo Henrique dos Santos. Novas tendências na estrutura fundamental do processo civil. Revista do Advogado, n 88 , nov. 2006, p. 145-172.

MARINONI, Luiz Guilherme. Novas Linhas do Processo Civil. 3. ed. - São Paulo: Malheiros, 1999.

. Curso de processo civil: teoria geral do processo(v.1).6. ed. - São Paulo: Revista dos Tribunais, 2012.

; ARENHART, Sérgio Cruz; MITIDIERO, Daniel. Novo curso de processo civil: teoria do processo civil. 3. ed. em e-book, baseada na 3. ed. impressa. São Paulo: Editora Revista dos Tribunais, 2017.

NERY JR, Nelson. Código de Processo Civil comentado [livro eletrônico]. 3. ed. São Paulo: Thomson Reuters Brasil, 2018.

NEVES, Daniel Amorim Assumpção. Manual de Direito Processual Civil. 10. ed. Salvador: JusPODIVM, 2018.

ORTEGA, Flavia. Qual a teoria da ação adotada pelo STJ e pelo Novo CPC? Disponível em: https://draflaviaortega.jusbrasil.com.br/noticias/422685152/qual-a-teoria-daacao-adotada-pelo-stj-e-pelo-novo-cpc. Acesso em: 15 maio 2020.

SAVIGNY, Friedrich Carl von. Sistema del diritto romano attuale. Trad. Vittorio Scialoja. v. 5. Torino: Utet, 1893.

SATTA, Salvatore. Direito Processual Civil. Trad. Luiz Autuori. 7. ed. - Rio de Janeiro: Editor Borsoi, 1973.

SILVA, OVÍDIO Araújo B. da. Jurisdição e Execução na tradição romano-canônica. 2. ed. - São Paulo RT, 1997.

SILVEIRA, Marco Aurélio Nunes da. A ação como elemento da trilogia fundamental do direito processual penal:a urgente necessidade de novos enfoques teóricos - uma crítica histórico-jurídica. Justiça do Direito. v. 28, n. 2, p. 278-305, jul./dez. 2014. 
TEODORO JÚNIOR, Humberto. Curso de direito processual civil. Teoria geral do direito processual civil, processo de conhecimento e procedimento comum. V.1. 57 a ed. ver. atual.eampl. Rio de Janeiro: Forense, 2016.

TESHEINER, José Maria Rosa; THAMAY, Rennan Faria Krüger. Condições da ação no novo CPC. 2017. Disponível em: http://www.rkladvocacia.com/condicoes-da-acaono-novo-cpc/. Acesso em: 20 de maio 2020

WAMBIER, Teresa Arruda Alvim (et al.). Breves Comentários ao novo Código de Processo Civil. São Paulo: RT, 2015.

WAMBIER, Luiz Rodrigues; TALAMINI, Eduardo. Curso avançado de processo civil. Teoria geral do processo. Volume 1. 16. ed. reformulada e ampliada de acordo com o novo CPC. Thomson Reuters. São Paulo: Revista dos Tribunais, 2016.

WATANABE, Kazuo. Da Cognição no Processo Civil. 3. ed. - São Paulo: Perfil, 2005.

WINDSCHEID, Bernard; MUTHER, Theodor. Polémica sobre la "actio". Trad. Tomás A. Banzhaf. Buenos Aires: Ejea, 1974.

YARSHELL, Flávio Luiz. Breves Notas sobre a Disciplina da Ação Rescisória no CPC 2015. In: BONATO, Giovanni (Coord.). O Novo Código de Processo Civil: Questões Controvertidas. São Paulo: Atlas, 2015. 